\title{
When should gallbladder polyps be treated surgically?
}

\author{
İbrahim T. Şahiner ${ }^{A-F}$, Mete Dolapç ${ }^{A, C-E}$ \\ Department of General Surgery, Hitit University School of Medicine, Çorum, Turkey \\ A - research concept and design; B - collection and/or assembly of data; $C$ - data analysis and interpretation; \\ $\mathrm{D}$ - writing the article; $\mathrm{E}$ - critical revision of the article; $\mathrm{F}$ - final approval of the article
}

\section{Address for correspondence \\ Ibrahim T. Şahiner \\ E-mail: tayfunsahiner@gmail.com}

\section{Funding sources}

None declared

\section{Conflict of interest}

None declared

Received on December 18, 2016

Reviewed on February 23, 2017

Accepted on July 4, 2017
DOI

10.17219/acem/75678

\section{Copyright}

Copyright by Author(s)

This is an article distributed under the terms of the

Creative Commons Attribution Non-Commercial License

(http://creativecommons.org/licenses/by-nc-nd/4.0/)

\begin{abstract}
Background. This study was performed to better understand the best surgery timing for gallbladder polyps (GP).

Objectives. The objective was to determine the potential for malignant transformation and the best timing for surgery in GP, based on an assessment of the clinical symptomatology and on the results of the imaging and histopathological examinations.
\end{abstract}

Material and methods. Age, gender, clinical symptoms, preoperative ultrasound findings, and the results of the postoperative histopathological examination were retrospectively assessed in a total of 2,656 patients undergoing cholecystectomy in Department of General Surgery, Hitit University School of Medicine, Çorum, Turkey, between 2008 and 2013.

Results. From a total of 2,656 patients undergoing cholecystectomy in our unit between 2008 and 2013, 96 subjects were found to have the following types of GP: 66.6\% $(n=64)$ had cholesterol polyps, $13.54 \%$ $(n=13)$ had adenomyomatous polyps, 8.33\% $(n=8)$ had adenocarcinoma, $7.2 \%(n=7)$ had inflammatory polyps, and $4.16 \%(n=4)$ had hyperplastic polyps. Also, $85.4 \%$ of these patients $(n=82)$ had a single polyp only, while $14.6 \%(n=14)$ had 2 polyps. The polyp size in patients with adenocarcinoma was $9 \mathrm{~mm}$, $10 \mathrm{~mm}$ and $12 \mathrm{~mm}$ in 2, 4 and 2 patients, respectively. The mean age of patients with adenocarcinoma was 60 years (55-74), all of whom had solitary polyps.

Conclusions. In patients over 50 years of age with co-existent cholelithiasis and GP exceeding $10 \mathrm{~mm}$, surgical treatment should be undertaken due to the risk of malignancy. Other patients with polyps less than $10 \mathrm{~mm}$ in size should be followed up in 6-month intervals using ultrasound examination.

Key words: gallbladder polyp, malignancy potential, surgery timing, ultrasonographic finding, gallbladder adenocarcinoma 


\section{Introduction}

Gallbladder polyps (GP), occurring in $0.3-12 \%$ of healthy individuals, arise from the mucosal layer and disrupt the integrity of the mucosa. ${ }^{1,2}$ Although their exact prevalence is currently unknown, an increase has been observed in the number of patients diagnosed with this condition, mainly due to the advances in diagnostic methods, to the increase in the proportion of individuals with access to healthcare facilities, and to the more widespread availability of ultrasound imaging. The majority of GP are asymptomatic and are diagnosed coincidentally during an abdominal ultrasound examination performed for other reasons. Gallbladder polyps may either be pseudo-polyps or true polyps. True polyps are further subdivided into benign (adenoma), pre-malignant (dysplastic) or malignant (adenocarcinoma) polyps. On the other hand, all types of pseudo-polyps are benign and are classified as inflammatory, hyperplastic, adenomatous, adenomyomatous, cholesterolotic, and cholesterol polyps. ${ }^{3}$ Cholesterol polyps are the most common. Although the prevalence of gallbladder cancer may reach up to $27 \%$ in individuals over 50 years of age, these lesions may be readily confused with benign polyps in ultrasound examination, especially in the early stages. Previous studies have suggested that polyps greater than $10 \mathrm{~mm}$ in size in patients over 50 years of age may pose an increased risk of malignancy. ${ }^{4-6}$ Ultrasound represents the most frequently used diagnostic imaging modality in the diagnosis of GP. However, since ultrasound does not always enable the examiner to differentiate between benign and malignant lesions, further imaging with advanced modalities, such as computed tomography (CT), endoscopic ultrasound (EUS) or magnetic resonance imaging (MRI), may be necessary. ${ }^{7}$

In this study, patients who had undergone cholecystectomy in the Department of General Surgery, Hitit University School of Medicine, Çorum, Turkey, were retrospectively examined with respect to the incidence of GP, polyp type and the occurrence of malignancy, as documented by the histology report.

\section{Material and methods}

Patients who had undergone cholecystectomy in our unit between 2008 and 2013 were retrospectively assessed with regard to the frequency of GP, polyp type, the frequency of malignancy, and the histopathological examination results. The study protocol was approved by the Institutional Review Board of Hitit University School of Medicine, Çorum, Turkey.

The structure, dimensions and number of polyps were evaluated using histopathological examination, and the polyps were sub-classified as pseudo-polyps (hyperplastic, inflammatory, adenomatous, adenomyomatous, cholesterolosis,, and cholesterol polyps) or true polyps (adenomas and adenocarcinomas). Also, the malignancy potential was examined on the basis of pathological examination. All clinical and demographic data was statistically evaluated using the SPSS software package v. 22 (IBM Corp., Armonk, USA). Frequency, minimum-maximum and mean values were recorded.

\section{Results}

A total of 2,656 cholecystectomies were performed in the Department of General Surgery, Hitit University School of Medicine, Çorum, Turkey, between 2008 and 2013. The mean age of the patients was 52 years (12-90); $79.3 \%$ $(\mathrm{n}=2,106)$ were female and $20.7 \%(\mathrm{n}=550)$ were male. Laparoscopic or open cholecystectomy was performed in $88 \%(\mathrm{n}=2,338)$ and in $12 \%(\mathrm{n}=318)$ of the patients, respectively.

All patients underwent ultrasound examination prior to surgery and the results are shown in Table 1.

Clinical symptoms included food intolerance in $10.6 \%$ of the patients ( $\mathrm{n}=282$ ), nausea and vomiting in $11.9 \%$ $(\mathrm{n}=318)$, right upper quadrant pain in $18.2 \%(\mathrm{n}=480)$, and dyspepsia in $59.3 \%(\mathrm{n}=1,576)$.

Table 1. Results of pre-operative ultrasound examination

\begin{tabular}{|l|c|c|}
\hline \multicolumn{1}{|c|}{$\begin{array}{c}\text { Result of pre-operative hepatobiliary } \\
\text { ultrasound examination }\end{array}$} & $\mathrm{n}$ & [\%] \\
\hline Acute calculous cholecystitis & 345 & 13 \\
\hline Acute cholecystitis & 66 & 2.5 \\
\hline Chronic cholecystitis & 40 & 1.5 \\
\hline Chronic calculous cholecystitis & 164 & 6.2 \\
\hline Cholelithiasis & 1,859 & 70 \\
\hline Gallbladder polyp & 159 & 6 \\
\hline Gallbladder sludge & 23 & 0.8 \\
\hline
\end{tabular}

$n$ - number of patients.

Table 2. Results of pathological examination

\begin{tabular}{|l|c|c|}
\hline $\begin{array}{c}\text { Results of postoperative pathological } \\
\text { examination }\end{array}$ & $n$ & {$[\%]$} \\
\hline Acute cholecystitis & 66 & 2.5 \\
\hline Acute calculous cholecystitis & 180 & 6.82 \\
\hline Chronic cholecystitis & 536 & 20.2 \\
\hline Chronic calculous cholecystitis & 1,726 & 65 \\
\hline Cholesterol polyp & 64 & 2.4 \\
\hline Adenomyomatous & 13 & 0.4 \\
\hline Xanthogranulomatous cholecystitis & 34 & 1.3 \\
\hline Hyperplastic polyp & 4 & 0.15 \\
\hline Adenomatous polyp & 8 & 0.30 \\
\hline Inflammatory polyp & 7 & 0.26 \\
\hline Adenocarcinoma & 18 & 0.67 \\
\hline
\end{tabular}

$n$ - number of patients. 
Table 3. Pathological results of postoperative pathological examination of the polyps

\begin{tabular}{|l|c|c|}
\hline $\begin{array}{c}\text { Results of postoperative pathological } \\
\text { examination of the polyps }\end{array}$ & $\mathrm{n}$ & {$[\%]$} \\
\hline Cholesterol polyp & 64 & 66.6 \\
\hline Hyperplastic polyp & 4 & 4.16 \\
\hline Adenomatous polyp & 13 & 13.54 \\
\hline Inflammatory polyp & 7 & 7.29 \\
\hline Adenocarcinoma & 8 & 8.33 \\
\hline
\end{tabular}

$n$ - number of patients.

The results of postoperative pathological examination of all subjects are shown in Table 2. A total of 96 subjects were found to have the following type of GP: cholesterol polyps in $66.6 \%$ of the patients $(n=64)$, adenomyomatous polyps in $13.54 \%(n=13)$, adenocarcinoma in $8.33 \%(n=8)$, inflammatory polyps in $7.29 \%(n=7)$, and hyperplastic polyps in $4.16 \%(n=4)$ (Table 3$)$. Also, $85.4 \%$ of these patients $(\mathrm{n}=82)$ had solitary single polyp only, while $14.6 \%$ ( $\mathrm{n}=14)$ had 2 polyps.

Table 4 shows the polyp size as determined by the pathological examination. The size of the polyp was $9 \mathrm{~mm}$, $10 \mathrm{~mm}$ and $12 \mathrm{~mm}$ among 2, 4 and 2 patients diagnosed with adenocarcinoma, respectively. All adenocarcinoma patients had solitary polyps and their mean age was 60 years (range: $55-74$ years).

Table 4. Polyp size as stated in the pathology report

\begin{tabular}{|l|c|c|c|c|c|c|}
\hline Polyp size [mm] & 4 & 5 & 7 & 9 & 10 & 12 \\
\hline Number of patients (n) & 14 & 63 & 11 & 2 & 4 & 2 \\
\hline$[\%]$ & 14.58 & 65.62 & 11.45 & 2.08 & 4.16 & 2.08 \\
\hline
\end{tabular}

\section{Discussion}

Polyps commonly occur in the gallbladder and their clinical significance arises from their potential for malignant conversion. The reported incidence of GP varies between $0.3 \%$ and $12 \% .^{8}$ A retrospective examination of the 2,656 patients undergoing cholecystectomy between 2008 and 2013 in the Department of General Surgery, Hitit University School of Medicine, Çorum, Turkey, showed the presence of GP in 96 individuals (3.6\%), which is consistent with literature data.

Some previous reports suggested that certain demographic characteristics, such as age or gender, may have an impact on the incidence of GP. ${ }^{8-10}$ Although gender was not found to have a significant effect on the occurrence of polyps in certain studies, others have generally reported a higher incidence among men. Notably, of the 96 patients with GP among the 2,656 individuals undergoing cholecystectomy, 73 (76.04\%) were female. While this observation may be due to the higher occurrence of GP among women, it may also be due to the fact that more women $(\mathrm{n}=2,016,79.3 \%)$ in our unit underwent cholecystectomy, which confirms the fact that gallbladder diseases are more common among women. A total of 52 patients (54\%) with GP were over 50 years of age, which is in line with data from previous publications.

Ultrasound is the most commonly used diagnostic modality in the diagnosis of GP. In the current study, all individuals $(n=2,656)$ had preoperative ultrasound examination, but only 159 (6\%) were sonographically diagnosed with GP. However, histopathology confirmed GP in only 96 individuals (3.6\%). This difference may be due to the level of expertise of the sonographer or to the small size of the polyps. Although polyps greater than $5 \mathrm{~mm}$ in size are more likely to be diagnosed by ultrasound, a size exceeding $10 \mathrm{~mm}$ greatly increases the chance of identification. Also, an accumulation of cholesterol and triglycerides on the gallbladder wall or the lamina propria by macrophages may give a false impression of polyps on the ultrasound. Table 3 shows the data from 96 patients with polyps assessed in our study. As the results suggest, there is a false positivity rate associated with the use of ultrasound in the detection of polyps. ${ }^{11}$

Another important criterion used when assessing GP is the size of the polyp. Literature data suggest an increased risk of malignancy in polyps larger than $10 \mathrm{~mm}$, with an even more marked increase in those over $12 \mathrm{~mm}$, though Kim et al. reported that a polyp size $\geq 15 \mathrm{~mm}$ is the strongest predictor of a neoplastic polyp with ultrasound and that the rate of malignancy is low even in polyps $10 \mathrm{~mm}$ or larger (15.1\%). ${ }^{4,9,12}$ Consistent with previous publications, only 2 of our patients with adenocarcinoma had polyps $9 \mathrm{~mm}$ in size, while the remaining patients had a polyp size ranging between 10 and $12 \mathrm{~mm}$. Similarly to the current study, Dorobisz et al. researched incidental gallbladder cancer after cholecystectomy. They performed 7,314 cholecystectomies (1990-2014) and found among them 84 cases $(0.87 \%)$ of incidental gallbladder carcinoma. ${ }^{13}$

\section{Conclusions}

In conclusion, we recommend surgery for all asymptomatic patients over 50 years of age who have GP greater than $10 \mathrm{~mm}$ in size, with or without cholelithiasis, because of the increased risk of malignancy. Other asymptomatic patients with polyps smaller than $10 \mathrm{~mm}$ should be followed up by ultrasound in 6-month intervals. An increase in the size or number of polyps or the emergence of symptoms during this period should prompt the consideration of surgery.

\section{References}

1. Hayashi Y, Liu JH, Moriguchi H, et al. Prevalence of polypoid lesions of the gallbladder in urban and rural areas of Japan: Comparison between 1988 and 1993. J Clin Gastroenterol. 1996;23(2):158-159.

2. Pandey M, Khatri AK, Sood BP, Shukla RC, Shukla VK. Cholecystosonographic evaluation of the prevalence of gallbladder diseases. A university hospital experience. Clin Imaging. 1996;20(4):269-272. 
3. Babu BI, Dennison AR, Garcea G. Management and diagnosis of gallbladder polyps: A systematic review. Langenbecks Arch Surg. 2015; 400(4):455-462.

4. Inui K, Yoshino J, Miyoshi H, Yamamoto S. Epidemiology of gallbladder carcinoma [in Japanese]. Nihon Rinsho. 2015;73(Suppl 3):541-544.

5. Jessurun J, Mendez-Sanchez N, Lopez-Acuna MP, Hernandez-Avila M, Uribe M. Epidemiology and various etiologic considerations in relation to carcinoma of the gallbladder [in Spanish]. RevGastroenterolMex. 1991;56(3):197-200.

6. Wang JH, Liu BJ, Xu HX, et al. Clinical, pathological and sonographic characteristics of unexpected gallbladder carcinoma. Int JClinExpMed. 2015;8(7):11109-11116.

7. Vijayakumar A, Vijayakumar A, Patil V, Mallikarjuna MN, Shivaswamy BS Early diagnosis of gallbladder carcinoma: An algorithm approach. ISRN Radiol. 2013;2013:239424.
8. Jo HB, Lee JK, Choi MY, et al. Is the prevalence of gallbladder polyp different between vegetarians and general population? Korean J Gastroenterol. 2015;66(5):268-273.

9. Sarkut P, Kilicturgay S, Ozer A, Ozturk E, Yilmazlar T. Gallbladder polyps: Factors affecting surgical decision. World J Gastroenterol. 2013; 19(28):4526-4530.

10. Ito $H$, Hann LE, D'Angelica M, et al. Polypoid lesions of the gallbladder: Diagnosis and follow-up. J Am Coll Surg. 2009;208(4):570-575.

11. FultzPJ, Skucas J, Weiss SL. Comparative imaging of gallbladder cancer. J Clin Gastroenterol. 1988;10(6):683-692.

12. Kim JS, Lee JK, Kim Y, Lee SM. US characteristics for the prediction of neoplasm in gallbladder polyps $10 \mathrm{~mm}$ or larger. Eur Radiol. 2016; 26(4):1134-1140.

13. Dorobisz T, Dorobisz K, Chabowski M, et al. Incidental gallbladder cancer after cholecystectomy: 1990 to 2014. Onco Targets Ther. 2016;9:4913-4916. doi: 10.2147/OTT.S106580 